\title{
Ethical and methodological issues in engaging young people living in poverty with participatory research methods
}

\author{
Daniela Sime, University of Strathclyde \\ daniela.sime@strath.ac.uk
}

\begin{abstract}
This paper discusses the methodological and ethical issues arising from a project that focused on conducting a qualitative study using participatory techniques with children and young people living in disadvantage. The main aim of the study was to explore the impact of poverty on children and young people's access to public and private services. The paper is based on the author's perspective of the first stage of the fieldwork from the project. It discusses the ethical implications of involving children and young people in the research process, in particular issues relating to access and recruitment, the role of young people's advisory groups, use of visual data and collection of data in young people's homes. The paper also identifies some strategies for addressing the difficulties encountered in relation to each of these aspects and it considers the benefits of adopting participatory methods when conducting research with children and young people.
\end{abstract}

Key words: participatory research; ethical issues; children in poverty; research in domestic spaces; use of visual data; young people's advisory groups.

\section{Introduction}

There is now an established respect for children's lived experiences and for their abilities to provide insightful accounts of how they understand and interpret these experiences (Christensen and James, 2000; Holloway and Valentine, 2000; Greene and Hogan, 2005). The new shift in the social studies of childhood initiated by writers such as James and Prout (1997) and James et al. (1998) views children as co-participants in the research process and stresses their competency and agency rather than seeing them as objects of research. Christensen and Prout (2002) argue that this shift from assumptions of dependency to a view of the children as competent participants in the research process involves the adoption of the notion of 'ethical symmetry' between children and adults, where 'the ethical responsibility between researcher and informant is the same whether he or she conducts research with adults or children' (2002: 482). This re-balance of the ethical relationship in the field re-assigns young people in a position of competence and empowerment and compels researchers to abandon the traditional views of children's vulnerability and incompetence. Morrow and Richards suggest then that respect for children's competencies 'needs to become a methodological technique in itself' (1996:110). The argument of this paper is that the ethical acceptability of research with children and young people and its validity can be enhanced by giving children a more active role in the research process through the use of participatory techniques when collecting data.

These changes in the social representations of children as empowered and competent and the increase in recognising children's rights have generated an upsurge in policy and practice initiatives in education, health and other services that place children's views to the fore. The adoption of the UN Convention of the Rights of the Child in 1989 which specifies in its Article 12 the right of the children to express an opinion on matters and decisions that affect them directly and to have that opinion taken into account meant an increased interest in involving young people through a range of participatory initiatives and consultations. This has led to studies that pose a considerable weight on the 
involvement of children as active participants and co-researchers (Kirby and Bryson, 2002; Sinclair, 2004) and has generated a wealth of literature on children's active role in research (Boyden and Ennew, 1997; Hill, 1997; Alderson, 2000; Kirby and Bryson, 2002; Kellett, 2005). Pain and Frances (2003) identify several advantages when using participatory methods with young people: they are particularly effective in accessing 'hard to reach' groups, participants choose the level of involvement, they are perceived as 'experts' and the collective solutions to participants' own priorities and interests emerge organically through shared discussions and use of research tools tailored to the participants. They also identify some of the limits pose by these methods and the barriers that researchers might be faced with, especially in relation to the follow up actions in specific social and political contexts.

Several authors have engaged in clarifying the precise links between participation and consultation (Morrow, 2000; Cutler, 2002; Hill et al., 2004) Hill et al. (2004) define participation as the 'direct involvement of children in the decision-making about matters that affect their lives', while consultation is about 'seeking views'. Both forms of involvement can enhance children's skills to contribute to policy formulation and service improvement, but can generate disillusionment if they do not result in change. Tisdall and Davis (2004) suggest that consultation on issues of policy is a first step in changing children's position as outsiders to insiders within the governmental structures and can lead to the successful translation of most of their views in policy documents.

Hill et al. (2004) consider participation as inextricably linked with social inclusion and propose the adoption of a coherent agenda for policy, practice and theory in order to move children's participation forward. There is now a wide range of policy initiatives that are aimed at tackling exclusion of families in deprived areas and especially of children and young people. However, these initiatives are still mainly developed and implemented by adults (Elsley, 2004), with little involvement from children and young people, who generally see themselves as excluded from local decision making processes (Sinclair, 2004). Also, the extent to which children and young people influence decisions about service provision is still limited (Hennessy, 1999; Kirby and Bryson, 2002). The few studies that have explored the direct experiences of children living in poverty have emphasised the impact of disadvantage on children's social relationships with peers (Middleton et al., 1995; Ridge, 2002) and on access to local services (Sime and Hill, 2005; Seaman et al., 2006). Recently, conscious steps are taken by policy-makers and practitioners to involve children and young people in decision making about services, local and national initiatives and even policy changes. This has direct implications for research conducted on child poverty, as researchers have an important role in promoting children's voices and using research as an empowerment tool.

\section{A participatory study on children's use of services in deprived areas}

The research project that I draw on for the purposes of this article aimed to explore children and young people's understandings on the impact of poverty on their access and use of public, private and voluntary services. Serving Children? The impact of poverty on children's use of public, private and voluntary services was a two-year project funded by a Big Lottery grant in partnership with Save the Children. Focussing on children and young people aged 10 to 14 years living in Scotland, the main purpose of the project was to inform a wide audience about young people's own experiences and views of services that they access. 
One of the aims of the project was to use a range of participatory techniques to promote young people's active involvement in the research process. Prior to writing the proposal, a group of ten young people were involved in a planning meeting, with the aim of informing the research on the key aspects related to young people's awareness of and use of services. The meeting aimed to identify issues that young people themselves deemed as important in relation to service provision and service use in deprived areas. These views were taken into account in the writing of the research proposal. Although the idea of the project emerged from the adult researchers, children's involvement in decisions about the main aspects of the research and its methodological design was key to the project. Young people provided insightful views into what counts as a 'service', barriers to access that the project might explore, what young people to involve, how to address the issue of poverty and best methods of data collection. This meeting, although facilitated by adults, gave young people control in exploring issues around what aspects of young people's service use would be researched.

The main data collection stage consisted initially of running discussion groups with fiftysix children and young people with ages between 10 and 14, in three research sites. A range of participatory techniques were involved in these meetings, to include exercises such as mapping, drawing and ranking. At the end of each discussion group, young people were given a disposable camera each to record their use of services for a week. Subsequent individual interviews were arranged with each young person, when children were invited to select the photographs they wanted to discuss and allowed to direct the conversation. The author was directly involved in the initial part of the data collection and the author's observations from this initial field work represent the basis for this article. The final findings from the study are presented elsewhere (Wager et al., 2007).

\section{Ethical aspects of doing research on poverty}

The ethical complexities of working with children and young people have been addressed by several authors (Alderson, 1995; Valentine, 1999; Christensen and James, 2000; Borland et al., 2001; Atkinson and John, 2001; Christensten, 2004; Greene and Hogan, 2005). However, there is a dearth of literature addressing the ethical issues of conducting research about poverty with children and young people. Admitting to poverty is a sensitive issue and many children may not perceive themselves as being poor. In the context of researching poverty with adults, there has been concern that the research process can actually contribute to the disempowerment of 'the poor' (Dean, 1996). However, Lister (2004) argues that involving people with experience of poverty in debates and consultations respects their rights and citizenship and it gives them status as full social partners. She also claims that participation increases deprived people's sense of their own agency and challenges the 'deficit model' of their passive situation, perceiving them as active contributors to society.

Research indicates that the 'p' words ('poverty' and 'poor') are often experienced as stigmatising labels and rarely used by people living in deprivation themselves (Corden, 1996; Dean and Melrose, 1999). Novak (2001) argues that these terms have become nowadays loaded with connotations and are stigmatising labels rather than descriptors. Dean and Melrose (1999) reported that two-thirds of the social security claimants did not see themselves as 'poor' and found alternative discourses to make sense of their circumstances. In Corden's (1996) study, people who actively participated in research about deprivation in their area were angry and disappointed when their neighbourhood was labelled as 'poor' by the researchers and media reports. Opinions are divided between 
those who think that the term 'poverty' should not be used at all when conducting research and those who claim that it should be used as a term for political action (Beresford et al., 1999). This raises an important ethical dilemma for researchers involved in working with people in deprived areas. On the one side, researchers should be respectful of the individuals' choices in terms of their perceived socio-economic status; on the other hand, by using a parallel discourse, the researchers may fail to use the findings as a means to empower the participants through research.

A small but growing number of studies have applied a participatory approach to researching childhood poverty (although see Middleton et al., 1995; Ridge, 2002), and while more research of this type is needed, these studies have begun to provide a picture of poverty from children's perspective. Lister (2004) points out that the shame and humiliation associated with living in poverty can be particularly difficult to bear by children and young people. Studies have also identified the damaging effects of the stigma associated with poverty on young people's identity and self-esteem (Ridge, 2002; Ermish et al., 2001). This raises the issue of the potentially negative effects that insensitive research may have on children's self-esteem. Given the negative and stigmatising connotations that the word 'poverty' has in the modern society, researchers involved in working with young people in deprived areas should be aware of the powerful effects of the discourse used. In the case of children, they may lack a wider experience of social differences in relation to how to assess their family's economic situation. In the interviews that I conducted, children often chose to talk about services that they used and had access to rather than elaborate on the services that were inaccessible, although they were aware of the nature of the barriers to accessing these services.

One ethical dilemma however remains in relation to the representation in research of children and young people who do not perceive themselves as living in poverty. Children who have developed social networks and information about available services are less likely to see themselves as excluded or 'poor'. Advocates of genuine participatory research claim that researchers have a responsibility to ensure that participants agree with the ways in which they are represented in research reports and on how research findings are used (Morrow and Richards, 1996; Thomas and O'Kane, 1998). One possible solution is to localise the research in terms of the characteristics of the geographical area in which the research took place, but acknowledge that not all individual participants saw themselves as living in deprivation. While researchers may assume that for people living in deprivation poverty is the first frame of reference, it may be the case that they accept their economic situation without it featuring as a constant preoccupation in relation to how they live their lives. The researcher's duty is to acknowledge that not all actors, in this case, people living in deprived areas and service providers or policy makers, share the same interpretation of a particular situation and that they all have the right to have their views represented accurately in the research outcomes.

\section{Ethical issues in negotiating access and consent}

One of the main challenges in doing research with children and young people is negotiating access at multiple levels with the adults that control the spaces suitable to conduct research with children, such as schools or children's clubs. This was one of the first challenges in the present study. Masson (2004) points out that these adult gatekeepers may not necessarily have a legal right to control children's decisions to participate, but they control the spaces that children and young people access. This means that negotiation of access takes place initially with adults at multiple levels (e.g. local Council- school 
management - teacher - parents) before the researcher has access to discuss the research directly with the young person. This is clearly a reflection of the society's view of the innocent child in need of protection and a denial of children's consent as valid in itself, regardless of the ethical requirements of eliciting children's own consent for participation in any research.

In the Serving children? study, children participating were usually sought through schools, although later on in the project other, more informal settings, like children's clubs or community organisations, were also used. When accessing schools, I first had to gain permission for access from the local authorities that we wanted to involve in the research, which required the submission of detailed research plans and often the clear identification of the schools in which we wanted access. This process, although following the existing standards in checking that research proposed is ethical, imposed an immediate selection of the children who could potentially express an interest in the research process. Although the use of free school meals is not always a reliable indicator, given that some families entitled might not claim them due to stigma, we used the existing data as a general indicator of deprivation and selected the schools based on these figures. A second layer of access was then represented by the school managers, who could decide if to accept the research in the school or not. In several cases, managers decided that given the curriculum constraints and other activities, such as forthcoming inspections or school festivities, the research would add an extra strain on teachers and pupils and therefore refused us access. In none of these cases were children consulted by the manager.

In schools where we had access, it was often a limited group of children (a class or two) that were invited to participate, again, based on decisions made by the school managers. While in some settings I was invited to talk to the participants about the project directly, in others, managers asked us to leave the information materials at the school and call or return later to confirm the names of interested pupils. This meant that the initial information about the project was often filtered by the managers' or teachers' own understanding of the materials and of their own views of the significance of the project. I had limited choice in such situations, as managers would often present this as the option most suitable for the school. This was more often the case in secondary rather than primary schools. I was also aware of the importance of establishing good relationships with the school managers for the effective running of the project later on at the data collection stage and often had limited choice but to accept their conditions.

A final level of scrutinised access took place through the children's parents. As local authorities require parental consent for most research done in schools, we offered to send a detailed information pack to the parents. These were distributed to the children who initially expressed an interest in the project at the school. They contained a user-friendly leaflet explaining the project and the children's involvement, a one page questionnaire about the family and a consent form that one of the parents were requested to sign. Although the materials emphasised that the research was carried out independently of schools and parents could return the forms confidentially, the response rate was extremely low, often under $10 \%$ of all forms distributed. This raises an important issue about requiring parental consent to involve children who want to take part in research. Atkinson and John (2001) have discussed the difficulties in accessing the 'hard to reach' participants in deprived areas. Several aspects may account for lower response rates in deprived areas mainly to do with complicated family circumstances (Ghate and Hazel, 2002), parental disengagement with schools (Reay, 2005), low levels of adult literacy or resistance to provide even minimal information about the family in a questionnaire. Schools are useful 
sites, as access to present the project and identify interested participants is negotiated usually for an entire group of children, ensuring better chances for identifying volunteers. However, researchers need to be aware of the powerful position that adults have over children in these settings, where children may think that participation would be appreciated by teachers or school managers, and the fact that access to wider groups is considerably reduced by the adult gatekeepers. In a school setting, the gatekeeper would usually identify the classes or groups that the researcher can contact to invite them to participate.

When negotiating access with adults, I found that success often depended on the researcher's personal skills and ability to convince the gatekeeper, usually in short phone conversations, that the research is worthwhile doing. There was often a sense of trying to 'market' the project to key adults in order to make sure that access to the child was granted. This introduced an element of unpredictability at the negotiation stage, as researchers often needed to make several phone calls before access was granted and the first visit was arranged. When phoning homes, mothers were most often the adults making the final decision on a child's participation. The predominant role of mothers in deciding on children's participation may be related to the dominant involvement of mothers in children's education (David, 2005; Reay, 2005). When parents do not respond or refuse consent, researchers can do very little in the case of the children who wish to participate and give their own consent. There were some of these instances in the Serving children? project and one solution that proved useful in this case was that of verbal instead of written consent. Parents were often more responsive in phone conversations, when I made sure that they have read the materials and asked any questions.

Ethical practice views informed consent, alongside other related concerns such as avoidance of harm and exploitation and respect for the participants' confidentiality and anonymity as central. Masson (2004) noted how in conducting research with children, adults will make decisions on children's competence to decide based on their own attitudes to childhood. In Scotland, parents have a duty to consult their children before exercising their rights to take decisions that involve their children (Children Scotland Act, 1995). However, as Mason notes: 'Where children can (...) understand the impact on them on participating, it may be more ethical to act on their consent than to require the fully informed consent of a parent. Such an approach gives children the maximum opportunity to have their views and experiences recorded and avoids the risk of exclusion of children whose parents would not respond to a request' (2004:50). This is especially relevant in deprived areas, where children may be excluded through parental disengagement.

Hill (2004) advises that consent should be obtained from the child in person, after the young person was given the opportunity to hear information about the project and ask questions or raise concerns. Although provision of information about the project may help children and young people in deciding if to get involved, in practice it is quite difficult for any participant, adult or young person, to understand the full implications of participating in research. Researchers may, for example, mention the methods that will be used and how findings will be used, but in reality, the research process is unpredictable for the participants (and often for the researcher!). Only after engaging with the actual topic of the project and becoming familiar with the content of the data generated, can the participants fully judge if to accept participation and use of information elicited from them for research purposes. 
Heath et al. (2004) discuss the role of 'process consent', where consent should be negotiated as an ongoing concern within the research process rather than something that it is assumed on the basis of initial consent. This appears to be the most ethical approach, as it gives participants full control at all stages of the research process. Edwards and Alldred (1999) use the concept of 'informed dissent' as a way of giving children and young people opportunities to refuse participation after the research has started. This refers to strategies such as offering children the option to read or solve a puzzle once in the room rather than contributing to the project. However, children and young people may feel under pressure to get involved especially when seeking participants through schools, and may think that non-participation would be penalised or would impact negatively on their relationship with the adult in control. To make sure that children who I tried to involve were genuinely interested in taking part, I emphasised the voluntary nature of the participation and ensured through individual conversations that young people understood the nature of their involvement and their right to withdraw at any point, without any negative repercussions. In three cases, young people chose not to follow up the first session with a one-to-one meeting and in one case, a child did not contribute at all to the group discussion. By using the process consent, research is respectful of young people's choice to withdraw consent explicitly or implicitly, through non-participation. However, the researcher must be prepared to face the logistical difficulties of a participant (or more) withdrawing from participating or withdrawing data later on in the project.

My experience also suggests that carrying out research with children and young people on their access to services often generates interest in research from participants who are already using a wide range of services. This means that certain disadvantaged groups remain 'hard to reach'. It also implies that although researchers may present the project as open to all young people, some may have limited experiences of service use and show little interest to talk about their reasons for not using available services. Children might also decide at the initial stage that because they are not high users of services, they might not have a lot to contribute to the project and therefore decide not to volunteer. Also, while creating the conditions for participation for all young people, researchers need to be aware that some may have little interest in participating and may see research as another activity initiated, organised and controlled by adults, with little direct benefit for them as individuals. Even if the role of the young people is more active in participatory research, there is an element of adult involvement that may configure the process as adultcontrolled. For example, there is often little involvement of young people in the actual writing of the research outcomes and dissemination.

Commonly, the practical ease of access to some children rather than others means compromises in terms of including in research any children that 'fit' the sample descriptions and excluding others. I often struggled to recruit boys from deprived backgrounds and further research needs to investigate the reasons why certain groups are more willing to get involved in research than others. There is also evidence to suggest that ethic minority children, younger children and disabled children are often absent from research (Hennessy, 1999; McNeish and Newman, 2002; Kirby and Bryson, 2002). More needs to be done to find ways of improving access to participation of the groups excluded until now. In the case of children living in poverty, this may include recruitment through other networks rather than schools and flexibility in terms of location of meetings and duration, as children may be under increased demands in the household due to challenging family circumstances. 
Finally, the issue of payment for contribution in research raises another ethical dilemma. I agree with Scott (2000) that children and young people should be equally valued for their participation in research in the same manner that adults are and should receive rewards for participation, whenever possible. Some find problematic the use of cash rewards with young people; in this case, gift vouchers for the child's choice of outlets or a group reward, if all participants agree to it, could provide safer options. While using incentives when asking participants to endorse products or services may be problematic, incentives to encourage participation in exploratory social research should not pose risks of compromising the findings. In this study, I used gift vouchers after each meeting as a token of appreciation for children's involvement, without giving any warning at the initial stage. Children were told that their participation in the second meeting with the researcher was independent of their gift and that they could keep the voucher from the first meeting if they subsequently decided to withdraw. The prospect of a reward may however make participants feel obliged to complete a study and affect their right to withdraw at any point, which means that researchers must ensure that payments or gifts are not conditioned by completion of the study.

\section{Involving young people's advisory groups in participatory research}

Alderson (2000) and Jones (2004) identify some of the ways in which children and young people can be involved directly in the processes of data collection and analysis. Little has been written however about the involvement of young people in advisory groups. In order to be successful and of benefit for both participants and research teams, young people's advisory groups need careful planning from the project proposal stage. In our project, provision was made for a young people's advisory group, with four proposed meetings for the duration of the project (over two years). However, once the project started, the need for another advisory group in a rural area was identified, as experiences of service use for children in urban and rural areas were found to be quite different. This shows once again the need for flexibility in adapting the original plans to the emerging needs that appear during the research.

I found that the issue of recruitment of advisors was key. The young people's advisory group was identified through existing contacts with a charity working with children in deprivation in the city of Glasgow. These young people were already participating in consultations about service improvement in the area and it was thought that their familiarity with the proposed research topic and with the concepts of consultation and research would benefit the project. All twenty-two young people involved with the charity were invited to apply to be 'advisors' on the project; only five expressed interest to do so and all were included in the advisory group. The same concerns about exclusion of 'hard to reach' young people discussed above apply here.

In order to give young people genuine opportunities for participation, I was open to young people's ideas on methods of data collection, on best ways to recruit young people in deprived areas and on how to deal with sensitive issues, such as payment or questions about poverty. They also provided a useful forum for initial analyses of the data and also for discussion of possible dissemination strategies. Although the research team found young people's involvement successful, there was a sense of limited contribution that young people could bring to the project. This is mainly linked to the time that young people could be reasonably asked to spend on familiarising themselves with the content of the project and with the data collection and dissemination techniques. While adult advisors are often given the full research proposal and selected as advisors on projects based on 
their specialist knowledge, young people have little access to the complex planning of the project and are often recruited in advisory groups mainly because of their age. I have tried to address these limitations by providing young people with a jargon-free summary of the project and with a list of 'topics' I found manageable in a two-hour meeting every six months. This raises issues about the genuine participatory value of the advisory groups. Genuine participation in advisory groups may require the researchers to compile accessible research proposals especially written for young people and ensure that young people have the time to fully understand the issues investigated and come up with meaningful contributions, otherwise the risk of disengagement and frustration may occur. Kellett (2005) also suggests that young people may require training in research methods if they are to contribute meaningfully to the research process.

Assuming a role that it is normally confined to adults may be daunting for young people and researchers need to ensure that meetings are not tokenistic and young people's contributions are given serious consideration in the research project. When asked to apply for the advisor post, all five young people in our project expressed confidence in their ability to contribute with good ideas and advice to projects and saw themselves as able to empathise with other young people and their problems. However, as meetings were planned only every six months, enthusiasm for the project was difficult to maintain among the young advisors, especially at the stages when involvement of advisors was less necessary, such as the actual data collection. Researchers may need to keep young advisors constantly informed on progress in the project and ensure than when meetings occur, advisors are in a position of making meaningful contributions.

\section{Using visual methods with children and young people}

Photography and video-based methods (Prosser, 2000; Kindon, 2003) present several advantages as a participatory methods. Children and young people engage in a range of rich practices of using complex media devices outside the school (Livingstone, 2002; McPake et al., 2004). By building on these competences, visual research methods become useful tools for participatory research with young people. They may also help children express their emotions and thoughts in ways that may be more difficult to express verbally. In the Serving children? project, I gave each participant a camera to take photographs of services that they used during a week. Although the focus on services was set by adults, young people had the freedom of deciding which aspects of their service use to include in their photographs, how many photographs to produce and when to take them. I also gave young people the option not to use the cameras and present their experiences in another format, but all chose to take the photographs. After the cameras were returned, two sets of photographs were printed, one for the research team and one for the young person. However, both sets were initially given to the young person, so that they could select any photographs which they did not want us to have. One-to-one conversations took then place with the children, to explore individual experiences of service use. In this process, photographs represented very useful aids for giving control over the meeting to the young person, as they could choose which photos to discuss, how long to spend on each photograph and what significance to give to each experience. The photographs also represented useful memory aids during the interviews, as they triggered detailed stories about experiences of service use.

Photographs can thus be used as a tool for addressing the power relationships between the researcher and the participants, as children can be given increased agency. If taking the photographs themselves like in our project, they have more control over the content of the 
photographs and they can also give their own perspective on the subject investigated. In this case, young people were able to represent in photographs services that were meaningful to them and then focus the interviews based on what they thought that was important in relation to the services in their area. However, the use of photographs with children and young people is not free from ethical concerns. Given the concerns raised in recent years by the upsurge in the use of child pornography, parents and other gatekeepers may show increased nervousness about allowing their children to contribute with photographic data. As current legislation with regard to photographs taken in public and private places is vague in relation to individual privacy and intrusion (Prosser, 2000), researchers may also be faced by denial of access in places like schools or children's clubs, if photography is involved.

An ethical concern in using photography with young people is therefore the issue of consent. Although parents may agree in the first instance with their children taking photographs at home or in their neighbourhood, they may disapprove of the content of the photographs once these are developed. In this study, a number of children took photographs of spaces in the home that may have offended the other family members through the intrusion of their privacy. Such examples included a mother sleeping, a young brother in underwear, the family bathroom or the contents of the fridge. Also, several children took photographs of their friends and other family members and as their consent to participate in the project had not been gained, it was considered that these photographs should not be used. This raises the issue of continuous consent in relation to visual data and of whose consent researchers need to seek: of the child? of the parents? and, also, of the other people represented in the photographs? As sensitive representations are more likely to appear in photographs taken in the home, it is reasonable to assume that families should have to right to exclude certain photographs if they find their content inappropriate or to accept their use for research purposes, but prohibit their use in any dissemination activities. In this study, I offered the families the copies and the negatives of any photographs that they wanted excluded.

In the process of collecting the photographs, young people engage in reflection on the research issues, as they decide on what to include or exclude from photographs. This benefit is however diminished when parents intervene and take over the project as they may think that the child needs 'help' in completing the task at hand, especially with younger children. In one of the cases in our sample, the child's mother drove to places that she thought were representative of the services that her child would use and she also took some of the photographs herself. These adult-led photographs were often more 'staged' and children made it clear in the interviews that these were adult-led choices and did not always accurately reflect their perspective. In these situations, follow-up interviews were crucial, as children were then afforded the opportunity to give their own perspective on the topic researched and elaborate on what their selection would have been without the adult's intervention. Researchers may reduce the risks of parents 'highjacking' the children's participation at the consent stage through clear emphasis on the non-judgemental and nonevaluative nature of the project and the importance of giving children control on the process.

\section{Ethical aspects of conducting research with children in their homes}

Conducting research with young people in their homes poses different challenges from research in other, more public spaces, like schools or children's clubs. Very little has been written about the construction of home as a research site and the ethical and 
methodological implications that arise from this (see however Mayall, 1994; Daly and Dienhart, 1999; Nilsen and Rogers, 2005). Research in schools often takes place in sport halls, staff rooms or empty classes, where participants have little control over the environment and are bound by more restrictive rules of interaction with adults. Choosing the home as a research site has increased advantages in terms of empowering the young participant, as the home may be perceived as a personal and familiar space where the researcher is a guest. However, homes are not spaces entirely controlled by young people and although they may offer a less formal setting, they are not free from ethical dilemmas. This is more so the case when doing research with children and young people living in poverty.

When, at the end of the group discussions, I asked young people to choose a place for our next one-to-one meeting, the majority of them chose their homes and asked the researcher to discuss with the parent a convenient time to visit. In two cases however, children did not want me to visit them at home and chose to meet in another location. In both cases, I decided to meet the participant in another setting, close to their homes in order to make it accessible (a park and a café in a bookshop). Researchers have a duty to ensure that home visits are not imposed on the child although they may form part of the planned methodology and should offer children alternative sites to meet.

Parents have total control of researchers' access to children in the home. Although children may perceive certain parts of the home as 'their spaces', domestic spaces are shared spaces and any research taking place in homes needs constant negotiations of access. Visits need pre-arrangements and often parents may decide to cancel visits at last minute or forget about arranged meetings. This was the case especially when trying to access children in deprived areas, whose parents were often under pressure to juggle difficult households and many times cited complicated circumstances (loss of employment, health problems, bereavement) as reasons for postponing or cancelling home visits. When parents do not have or refuse to give a contact telephone number, the researcher may need to make multiple visits to find the family at home. Difficulties in negotiating access may mean a constant pressure of being flexible and willing to compromise. I often felt the need to keep visits short when visiting crowded households or families with complicated circumstances. Often, parents would set out the limits on how long the meeting could last (one parent reasonably asked in a visit: 'Will you finish by dinner time?') In these situations, researchers may also develop hesitations to ask for follow-up visits and pressures not to be too demanding.

The fact that the researcher needs to arrange home visits with the parent in the first instance, often with more than a week of notice, may mean that on the day of the visit the young person may not be willing to participate. In one case, I arrived at a child's home to find him outside playing with his friends. Although the child was pleased to see me, the fact that he was called inside to participate in the interview by his mother made him unhappy and he withdrew during the meeting. This raises an important ethical dilemma for the researcher, as although the child gave his verbal consent to the interview taking place, his non-verbal messages suggested reluctant participation. In this case, I kept the meeting very short and offered to re-arrange another meeting with a child at a better time, if he wanted to. In such cases, although the researcher may offer to return, children may feel under pressure from parents to comply with the role of a polite guest and complete the interview. 
Another important role that adults and other family members play in terms of gatekeeping takes place during the actual home visits. Parents are almost always the ones who decide the spaces that the researcher accesses immediately after entering the home, by explicitly indicating where the meeting will take place. Although in several occasions children that I visited opened the door and invited me in, on some occasions one of the parents (usually the mother) was present and made clear where the conversation with the child was supposed to take place. Sometimes, mothers had a room set up already when I arrived, usually the living room, with chairs, tea and biscuits ready, and mother and child prepared to take part.

However, when visiting families in their homes, the researcher may be faced with a completely different situation, arriving at an inconvenient time. Despite informing families of the time of the visits, I often found families sleeping, returning from shopping or watching a favourite programme and I was caught in a dilemma, as visits were difficult to negotiate and arrange and at the same time I did not want to inconvenience the family and make participation in research uncomfortable. In these situations, I offered to return at a more convenient time or later in the day, if parents agreed. This is a note from such a visit:

Nicky did not give a contact telephone number on the form and the letters to her family to ask for consent remained unanswered. However, Nicky said that her mother would agree to the home visit and that I could visit in the afternoon. I made three unsuccessful visits as the family was not at home. At the forth attempt, Nicky's mother opened the door in pyjamas and after I apologised, I asked if it would be all right to chat with Nicky about the project, maybe at a more convenient time. She invited me in, saying that I could do the interview on the spot, but that I should go to Nicky's bedroom upstairs as the mother was watching TV in the living room. I asked if we could chat in the kitchen instead, but the mother insisted that Nicky's bedroom would be the only suitable space. During the interview, which lasted around forty-five minutes, the mother did not come upstairs and when I left, I asked Nicky if I could say 'good bye' to her mother. Her mum was however sleeping, so I left.

The above example raises important issues in relation to the researcher's own protection when collecting data in homes. On one other case, I arrived at a child's home to find the child alone, but with the specific permission from the parent to go ahead with the meeting while she was out shopping. Accessing children without any adult intrusion, although desirable as it offers the child with privacy and best conditions for recording, may make some researchers uncomfortable with the risk of potential accusations of harm. As this is at the latitude of the researcher and no regulations exist in relation to this, caution is suggested especially with younger children. In these situations, the researcher may choose to leave the bedroom door open or to insist on another, more public location, if feeling uncomfortable.

In other situations, adults may insist in being present during the meeting with the child and may even interfere in the research process. In most cases, children were specific about their intention to conduct the interview without an 'audience' and the other family members were respectful of their choice. However, I sometimes found an adult or sibling ready to listen and often participate in the interview, which meant that, potentially, the child's right to confidentiality was affected. This is an extract from a field note made after one of the visits:

I arrived at Joanna's house at around $11 \mathrm{am}$, as agreed on the phone with her mother. Mrs S opened the door and invited me in the living room. Here, her older son was watching TV together with a friend and Joanna's sister was playing on the computer. Joanna was seating on the sofa waiting for me. Mrs S offered tea or coffee and invited me to sit on the sofa, next to Joanna. She then asked me if it would be all right to conduct the interview in the living room, as the boys would silence the TV 
and she would be in the kitchen. I asked Joanna if she would prefer to talk somewhere more private and she responded she would like to stay in the living room. During the interview, her mother popped in and out of the room and the other children in the room listened to the conversation, but did not interrupt at any point.

Given the guest status of the researcher in such situations, there is little that a researcher can do to limit the others' involvement in the interview, especially when the participant children themselves feel obliged to accept the presence of an adult or sibling. This also raises the issue of consent for research from the other participants in the interview, as initially consent is sought only from the child or young person identified for the purposes of the project. In one case, the grandmother was present during the whole interview and later on the girl's father also came into the room to listen and contribute to the conversation. This is an extract from the transcript of the visit:

Researcher: Do you go to any clubs?

Tracey, 10: $\quad$ Yes, I go to dancing on Fridays.

Researcher: How do you get there?

Tracey, 10: $\quad$ My mum drives me.

Researcher: And do you pay for classes from your pocket money?

Grandmother: Well, your mum pays for everything, doesn't she? You get everything paid for, you don't need pocket money.

and later on:

Researcher: What about hospitals? What do you think of them?

Tracey, 10: $\quad$ I was there once, when I was very ill...

Grandmother (addressing the researcher): Could we move on, please?

If parents perceive the need to control the information that children give to the researcher, either by contradicting, completing or answering the researcher's questions in their place, the researcher can do little to limit the adult's contribution if specific requests to allow the child to put their views across are ignored by the carer. In these cases, data collected with parental supervision or control need to be considered with care in the analysis.

One final aspect of the data collected in children's homes relates to the data that are elicited through the researcher's own observations of the family's living conditions or of the events that occur in the background during the research visit. As the study concerned the impact of poverty on children's access to and use of services, it was thought that information generated by the researcher's impressions on the family living conditions, their relationships with the participating child, overheard conversations between siblings etc. would be a resourceful set of data in relation to children's economic and social capital. For example, in one of the visits, the researcher was told by one of the children that her weekly allowance of pocket money was $£ 52$, which came as a surprise given an overheard conversation between her mother and her brother on lack of money to buy lunch for the day. In one other situation, the absence of a father became clear through an overheard phone conversation about the visiting time at the prison he was held in. As parents may understand consent as permission to conduct a discussion with the child in the home, data collected through observations during the home visit may not represent ethically acceptable information. This raises issues in relation to how explicit the purpose of the visits should be so that consent is fully informed. 


\section{Being reflexive in the field}

An ethical aspect that it is worthwhile mentioning is the impact of the researcher's own identity on the data collection and analysis processes and the importance of adopting a reflexive approach in the field. In this project, I was aware of the impact that the participants' impressions about how I presented herself had on the interaction process and the relationships that were built in the field.

In relation to how a researcher presents himself/herself to families living in deprivation, there are important decisions to be made in terms of building a rapport and supporting the adult's decision to invite the researcher to their home and the need to explain the investigatory nature of the home visit. While the status of an academic researcher may intimidate some parents, researchers need to be clear about the purposes of the visit, yet find ways of empowering the parents through the use of accessible language and a friendly manner. Furthermore, the research topic may pose a problem in itself, if parents might consider the research as intrusive or perceive the researcher as belonging to a group of professionals that aim to 'colonise' their family life. The term 'service', for example, may generate negative associations in parents with negative experiences of child protection agencies or social services. In the case of perceptions of services in deprived areas, Ghate and Hazel (2002) found that parents often felt that services might try and impose their own 'rules' on family life and accessing certain services would affect a person's control over the situation and their privacy. I therefore found it important to clarify that the research was interested in children's own views of services and that it was not funded or initiated by any service providers.

In establishing rapport, I found that identifying commonalities with the parent was very useful. My own background was often subject of discussion during the first phone contact and the first minutes of the home visits. There were several factors that could have separated me as a researcher and the participating families (Researcher/Parent: 'Romanian'/'Scottish', 'young female'/ 'more mature female', 'childless'/ 'parent', 'researcher'/ 'mother', 'more affluent'/'living in disadvantage', 'experience of education'/'less experience of education'). However, these apparent differences provided however an excellent opportunity for building rapport, initially through the adults' interest in my own life story and then through the finding of a common ground in discussions about poverty in my own country and in Scotland. I was often asked if people were 'poorer' in Romania and if I understood well the local language. At times, it was not clear which of my identities was predominant in my interactions with the parents.

These apparent differences between the families' backgrounds and my own experiences presented another unanticipated advantage: in our discussions, parents and children felt that they needed to better explain their use and understanding of services, as they thought I might not be familiar with the Scottish context. Other authors have pointed out that race and gender may have a negative impact on the research interactions if perceptions of such factors differ between cultures (Bhopal, 2000; Shah, 2004). I suggest that if the researcher is prepared to allow participants to explore the researcher's own personal identity, the research relationship becomes more balanced and differences of status, cultural background, gender etc. may turn into an advantage rather than a barrier. 


\section{Concluding Comments}

In this paper, I have explored some of the ethical dilemmas that I encountered when conducting research with children and young people in deprived areas. The paper has discussed some of the possible ways of involving children and young people as more active participants in the research process through the use of participatory methods and a flexible approach to the settings where research is conducted.

In relation to conducting research in young people's homes, researchers need to be prepared to be flexible in terms of collecting data and ready to make ethical decisions during as well as before entering the field. The specific situational contexts will condition the nature of the relationships that develop with children and their parents and the research design may need spontaneous alterations. Rather than considering ethics as a pre-stage of field work, researchers need to be prepared to deal with ethical issues emerging in the field and should reflexively engage in decisions in relation to these. Homes need to be considered as complex, unpredictable settings that are likely to configure the nature of the research relationships and of the data collected in every single encounter. The researcher's main role is to find a harmonious balance between the children's active participation in the project and the parents' concerns. The practical constraints that may affect the data collection need also careful consideration when planning to collect data through home visits.

Research needs to be a positive and empowering experience for children and young people participating. It is the researcher's moral responsibility to ensure that the existing practice guidelines are respected and that children are protected through participation. However, guidelines may not always offer answers to the complex issues that may emerge in the field and researchers need to be mindful of these. Finally, researchers need to make sure that reports reflect children's own views in a positive and unstigmatising manner, with respect for children's rationality and their dignity.

\section{Acknowledgments}

I am grateful to all young people and their families for participating in the research on which this paper is based and Save the Children and the Lottery Fund whose financial support made the research possible. I would like to thank Malcolm Hill, Robina Goodlad, Susan Elsley, Douglas Hamilton and Caroline King for the rich discussions that shaped the initial stages of the Serving children? project and informed my thinking on the issues discussed here. I am also grateful to the two anonymous reviewers and the editors for their very useful comments on a previous draft of this paper. 


\section{REFERENCES}

ALDERSON, P. (1995) Listening to Children: Children, ethics and social research. Ilford: Barnardo's.

ALDERSON, P. (2000) Children as researchers: the effects of participation rights on research methodology, In P. Christiansen and A. Prout (eds.) Research with Children: Perspectives and practices, New York: Falmer Press, pp. 241- 257.

ATKINSON, R., \& JOHN, F. (2001). Accessing hidden and hard-to-reach populations: Snowball research strategies. In N. Gilbert (Ed.), Social Research Update. Surrey: University of Surrey.

BERESFORD, P., GREEN, D., LISTER, R. \& WOODARD, K. (1999) Poverty First Hand, London: CPAG.

BHOPAL, K. (2000) Gender, 'race' and power in the research process, In C. Truman, D.M. Mertens \& B. Humphries (eds.) Research and Inequality, London: Routledge, pp. 67-79.

BORLAND, M., HILL, M., LAYBOURN, A. \& STAFFORD, A. (2000) Improving consultation with children and young people in relevant aspects of policy making and legislation in Scotland, Edinburgh: Scottish Parliament.

BOYDEN, J. and ENNEW, J. (1997) Children in Research: A manual for participatory research with children, Stockholm: Radda Barnen.

CHRISTENSEN, P. (2004) Children's participation in ethnographic research: Issues of power and representation, Children \& Society, 18(2), pp. 165-176.

CHRISTENSEN, P. \& JAMES, A. (Eds.) (2000) Researching with Children: Perspectives and practices, London: Falmer Press.

CHRISTENSEN, P. \& PROUT, A. (2002) Working with ethical symmetry in social research with children, Childhood, 9(4), pp. 477-397.

CORDEN, A. (1996). Writing about poverty: Ethical dilemmas. In H. Dean (Ed.), Ethics and Social Policy Research. Luton: University of Luton Press.

CUTLER, D. (2002) Taking the Initiative, London: Carnegie Trust.

DALY, K. AND DIENHART, A. (1998) Navigating the family domain: qualitative field dilemmas, In S. Grills (ed.) Doing Ethnographic Research: Fieldwork settings, Thousand Oaks, CA: Sage, pp. 97-121.

DAVID, M.E. (2005) Activating Participation: A personal reflection on research on mothers and education, In G. Crozier and D. Reay (eds.) Activating Participation: Parents and teachers working towards partnership, Stoke on Trent: Trentham Books, pp. 3-21.

DEAN, H. (1996). Introduction. In H. Dean (Ed.), Ethics and Social Policy Research. Luton: University of Luton Press.

DEAN, H. \& MELROSE, M. (1999) Poverty, Riches and Social Citizenship, Basingstoke: Macmillan.

EDWARDS, R. \& ALDRED, P. (2001) Children and young people's views of social research: the case of research on home-school relations, Childhood, 6, pp. 261-281.

ELSLEY, S. (2004). Children's experience of public space. Children \& Society, 18, pp. $155-164$.

ERMISCH, E., FRANCESCONI, M. \& PEVALIN, D.J. (2001) Outcomes for Children of Poverty, Leeds: DWP/Corporate Document Services.

GHATE, D., \& HAZEL, N. (2002). Parenting in Poor Environments, London: Jessica Kingsley.

GREENE, S. \& HOGAN, D. (eds.) (2005) Researching Children's Experience: Approaches and methods, London: Sage. 
HEATH, S., CHARLES, V., CROW, G. AND WILES, R. (2004) Informed consent, gatekeepers \& go-betweens, Paper presented to the stream on 'The Ethics \& Social Relations of Research', Sixth International Conference on Social Science Methodology, Amsterdam, August 2004

HENNESSY, E. (1999). Children as service evaluators. Child Psychology \& Psychiatry Review, 4(4), 153-161.

HILL, M. (1997) Participatory research with children, Child and Family Social Work, 2(3), 171-183.

HILL, M. (2004) Ethical considerations in researching children's experiences, in S. Greene and D. Hogan (eds.) Researching children's experience: Approaches and Methods, London: Sage, pp. 61-85.

HILL, M., DAVIS, J., PROUT, A. AND TISDALL, K. (2004) Moving the participation agenda forward, Children \& Society, 18 (2), pp. 77-96.

HOLLOWAY, S.L. \& VALENTINE, G. (2000) Children's geographies, London: Routledge.

JAMES, A. \& PROUT, A. (1997) Constructing and Reconstructing Childhood: Contemporary issues in the sociological study of childhood, London: Falmer Press.

JAMES, A., JENKS, C. \& PROUT, A. (1998) Theorising Childhood, Cambridge: Polity Press.

JONES, A. (2004) Children and Young People as Researchers, In S.Fraser, V. Lewis, S. Ding, M. Kellett, C. Robinson (eds.) Doing Research with Children and Young People, London: Thousand Oaks, pp. 113-131.

KELLETT, M. (2005) Children as active researchers: a new research paradigm for the $21^{\text {st }}$ century?, ESRC National Centre for Research Methods.

KINDON, S. (2003) Participatory video in geographic research: A feminist practice of looking?, Area, 35(2), 142-153.

KIRBY, P., \& BRYSON, S. (2002). Measuring the Magic? Evaluating and researching young people's participation in public decision making. London: Carnegie Young People Initiative.

LISTER, R. (2004). Poverty, Cambridge: Polity Press

LIVINGSTONE, S. (2002) Young People and New Media: Childhood and the changing media environment, London: Sage

MASSON, J. (2004) The Legal Context, In S. Fraser, V. Lewis, S. Ding, M. Kellett and C. Robinson (eds.) Doing Research with Children and Young People, London: Thousand Oaks, pp. 43-59.

MAYALL, B. (1994) Children in action at home and school, In B. Mayall (ed.) Children's Childhoods: Observed and experienced, London: Falmer Press, pp. 114-127.

MCNEISH, D., \& NEWMAN, T. (2002). Involving children and young people in decision making. In D. McNeish,T. Newman, \& H. Roberts (Eds.), What Works for Children? Buckingham: Open University Press, pp. 186-206.

MCPAKE, J., STEPHEN, C., PLOWMAN, L., SIME, D. AND DOWNEY, S. (2004) Already at a disadvantage? ICT in the home and children's preparation for primary school, BECTA Report.

MIDDLETON, S., ASHWORTH, K., \& WALKER, R.E. (1995) Family Fortunes: Pressures on parents and children in the 1990s London: CPAG

MIDDLETON, S., ASHWORTH, K., \& BRAITHWAITE, I. (1997) Small Fortunes: Spending on children, childhood poverty and parental sacrifice. York: Joseph Rowntree Foundation.

MORROW, V. (2000) 'It's cool...cos' you can't give us detentions and things, can you?': Reflections on research with children, In P. Milner \& B. Carolin (eds.) Time to Listen to Children, London: Routledge, pp. 203-215. 
MORROW, V. \& RICHARDS, M. (1996) The ethics of social research with children: an overview, Children \& Society, 10(2), pp. 90-105.

NIELSEN, R.D. \& ROGERS, B. (2005) 'That's not a good idea, mom': Negotiating children's subjectivity while constructing 'home' as a research site, Children's Geographies, 3(3), pp. 345-362.

NOVAK, T. (2001) What's in a name? Poverty, the underclass and social exclusion, In M.Lavalette and A. Pratt (eds.) Social Policy: A conceptual and theoretical introduction, London: Sage.

PAIN, R. \& FRANCIS, P. (2003) Reflections on participatory research, Area, 35(1), pp. 46-54.

PROSSER, J. (2000) The moral maze of image ethics, In H. Simons and R. Usher (eds.) Situated Ethics in Educational Research, London: Routledge Falmer

RIDGE, T. (2002) Childhood Poverty and Social Exclusion: From a child's perspective, York: Policy Press

REAY, D. (2005) Mothers' involvement in their children's schooling: Social Reproduction in Action?, in Croazier, G. and Reay, D. (eds.) Activating Participation: Parents and children working towards partnership, Stoke on Trent: Trentham Books.

SCOTT, J. (2000) Children as respondents: The challenge for quantitative methods, In P. Christiansen and A. Prout (eds.) Research with Children: Perspectives and practices, New York: Falmer Press, pp. 98-119.

SEAMAN, P.; TURNER, K.; HILL, M.; STAFFORD, A.; WALKER, M. (2006) Parenting and children's resilience in disadvantaged communities, Joseph Rowntree Foundation.

SHAH, S. (2004) The researcher/interviewer in intercultural context: a social intruder!, British Educational Research Journal, 30(4)

SHENTON, F. (1999) Evaluation of the county Durham 'Investing in children's initiative'. Durham: University of Durham.

SIME, D. \& HILL, M. (2005) 'I like the Monday club, because you meet with friends, but you need money to have fun' The impact of poverty on children's experiences of public, private and voluntary services, Childhoods Conference paper, Oslo.

SINCLAIR, R. (2004). Participation in practice: Making it meaningful, effective and sustainable. Children \& Society, 18, pp. 106-118.

TISDALL, K. AND DAVIS, J. (2004) Making a difference? Bringing children's and young people's views into policy-making. Children \& Society, 18, pp. 131-142.

THOMAS, N. \& O'KANE, C. (1998) The ethics of participatory research with children, Children \& Society, 12, pp. 336-348.

VALENTINE, G. (1999) Being seen and heard? The ethical complexities of working with children and young people at home and at school. Ethics, Place and Environment, 2(2), pp. 141-155.

WAGER, F.; BAILEY, N.; DAY, R.; HAMILTON, D.; HILL, M.; KING, C. (2007) Serving children? The impact of poverty on children's experiences of public, private and voluntary services, Edinburgh: Save the Children. 